\title{
A new stage in the development of housing construction
}

\author{
Pavel Oleynik*, Lilia Pakhomova \\ Moscow State University of Civil Engineering (National Research University), 129337, \\ Moscow, Russia
}

\begin{abstract}
The perspective development of large-modular housing construction is considered as an important area of a significant increase in the pace and volume of housing construction. The analysis of the manufacture and use of blocks used for container mobile buildings for industrial and auxiliary purposes, as well as aggregated blocks for complete block construction of oil and gas facilities is given. The types of block modules of large-scale residential buildings and the technological sequence of their installation are indicated. The problems of transportation of block modules and mechanization of their lifting and installation in the design position are formed and analyzed, and the ways of their solution are revealed.
\end{abstract}

\section{Introduction}

The priority vector of development in modern housing construction is the provision of highquality and affordable housing. To solve this problem, a new round of industrial housing construction is required, which primarily includes large-scale housing construction. An important aspect of this area is a significant increase in the pace of housing construction, especially in the free territories of New Moscow. In this case, the pace of construction will be determined by the productivity of the plant manufacturing block modules $[1,9]$.

\section{Materials and methods}

The basis of large-scale housing construction is the experience in manufacturing and using mobile buildings and using the complete block method of construction $[7,8]$.

The technical necessity and economic feasibility of the manufacture and use of mobile buildings was justified by the requirements for creating normal production and living conditions for workers at construction sites. By 1975, the enterprises of the ministries and departments of the country had produced about 200 thousand mobile buildings, 214 thousand buildings of a container type and 2,085 thousand $\mathrm{m}^{2}$ of collapsible buildings, which replaced ineffective (temporary) buildings used in construction. From such buildings, the sets were formed for various construction organizations, taking into account their specifics. In turn, the sets consisted of several mobile buildings and structures for

${ }^{*}$ Corresponding author: OleynikPP@mgsu.ru 
specific construction sites. So, for example, temporary construction camps were formed from container buildings up to 3 floors, blocking them along the width or length of the building. Container buildings were designed mainly according to panel or frame-cladding constructive scheme. In both cases, the frame of the panel or the entire building was made of steel bent or rolled profiles with an auxiliary wooden or fullwooden frame, the exterior paneling, as a rule, consisted of sheet materials - steel, aluminum, water-resistant plywood.

The base of the container was often in the form of a strong frame made of rolled steel profiles.

The complete block method was proposed in the late 60 s of the XX century and was widely used in the construction of oil and gas facilities in Western Siberia. As a result, for example, during the construction of both processing and oil and gas transportation enterprises, the standard construction time was reduced by $20-25 \%$, while labor costs at the construction site were reduced by 2-3 times. The complete block method is a method of erecting objects using blocks of various types and purposes of high or complete factory readiness. The development of this method was provided by such measures as:

- -transition to the principles of modular design of buildings and structures as a synthesis of block-modules of technological equipment with supporting and enclosing structures;

- development and serial production of high-performance small-sized technological equipment of increased reliability;

- creation of new effective structural and heat-insulating materials and development on their basis of rational design solutions for supporting and enclosing structures.

The objects recommended in the complete block design were subdivided into the following groups:

1 - a large mass of blocks ( $92 \%$ of blocks up to 300 tons, the rest - up to 600 tons) and the absence of the need for the construction of buildings and structures;

2 - open stacks with blocks located on floors (97\% of blocks weigh up to 60 tons, and the rest do not exceed 120 tons);

3 - one-storey buildings ( $98 \%$ of blocks weigh up to 60 tons, and the rest have a mass of 100 tons);

4 - multi-storey buildings ( $97 \%$ of blocks weigh up to 50 tons, the rest of blocks do not exceed 70 tons).

As a rule, when installing blocks in single-storey buildings, the mass of the main blocks did not exceed 300 tons, and in multi-storey buildings - 50 tons. At the same time, the maximum dimensions of blocks with a mass of up to 600 tons were $18 \times 30 \times 36 \mathrm{~m}$, and the rest of blocks $-6 \times 12 \times 72 \mathrm{~m}$.

The units were installed in the design position by such lifting cranes as SKR-2600, SKR-2200, SKR-3500, SKG-100, SKG-160, MKG-100. In the method of "sliding" blocks, assembly winches, jacks, pulley blocks of the appropriate carrying capacity were used. When erecting pavilion-type buildings, taking into account the large mass of blocks, such transport and assembly equipment as Kommeto (Italy), Scheuerle (Germany), and Nicholas (France) were used.

The initial materials for the development of a construction organization project based on the complete block method additionally included:

- technical characteristics of blocks that determine the conditions for their transportation and installation;

- information on the conditions for providing construction with special transport for the transportation of blocks and the availability of heavy-duty cranes, technological equipment, devices for installing blocks in the design position;

- data on the presence and capacity of assembly enterprises in the construction area or other bases that can be adapted for the manufacture of blocks. 
Nowadays, the construction of large-scale buildings is carried out using the following types of modules:

- building block modules erected in building conditions(Fig. 1);

- factory-madebuilding block modules (Fig. 2);

- low-rise light module buildings (Fig. 3.);

- oversized modules - factory-made products of the maximum size, which enclose a closed volume of a part of the building, intended for the placement of one or a group of rooms, which, if necessary or at the request of the customer, can be completely finished and equipped at the factory (Fig. 4);

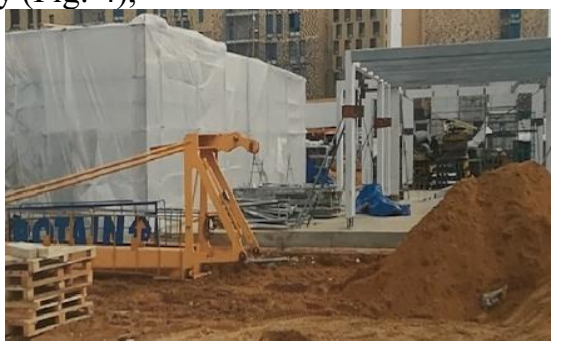

Fig.1. Building block modules erected in building conditions.

The technological sequence for the construction of large-scale residential buildings is as follows:

- a building is being erected at the construction site;

- modules are manufactured at industrial factories for large-scale housing construction;

- ready-made modules are installed on a prepared foundation;

- modules are installed on top of each other (in a multi-storey version) and interconnected;

- joints are sealed;

- finishing of those places that cannot be done in the factory is completed.

\section{Research and experiments}

To determine the necessary additional equipment, machines and mechanisms for large-scale housing construction, research and experiments are being carried out:

1. The weight of oversized modules can reach a maximum of 80 tons. To lift and move the modules, it is necessary to develop a special load-gripping device consisting of a sling, a traverse, and special grips, with the possibility of automatic guidance of the traverse when slinging and unslinging the mounted module, using the method of "mounting from wheels" at the construction site, as well as installing the module in the design position. Thus, the problems of the presence of slingers and the use of additional equipment for slingers to be near the mounted module at a height are solved.

2. In the early periods of the development of industrial housing construction, building blocks were used. However, housing construction using building block modules did not receive its further development at that time due to unsolved problems - these are difficulties in transporting building block modules from the place of their production to the place of installation and the lack of the necessary equipment for the installation of building block modules on the construction site. However, at present, with the development of technology, it has become possible to return to the idea of developing housing construction using building block modules at a new stage of development, and one of the leading areas has become the development of large-scale housing construction, the prototype of which was housing construction using building block 
modules. After 90 years since the first design and construction of residential buildings using building block modules, the requirements for living conditions have changed and the production of modules has reached a new level. All manufacturing processes are automated, with the help of robots, in a warm environment with the exception of negative climatic conditions. Accordingly, the quality of the modules produced in the factory is quite high. The module is manufactured in full maximum factory readiness.

It was previously noted that the weight of an oversized module can reach a maximum of 80 tons. Due to the large dimensions of the transported modules and the large weight during transportation from the plant where they were manufactures to the construction site, it was necessary to conduct research and experiment. In preparation for the experiment on the transportation of modules, many different studies were carried out, one of which is the installation of a pre-calculated and designed brace to ensure the perception of additional dynamic loads during the transportation and installation of large-sized modules. Before the start of the transportation of modules, sensors were installed - beacons, which recorded various types of deformations during the transportation of modules. As a result of the experiment, the installed brace inside each transported module justified its need. Part of the loads fell on it, and the spatial rigidity of the transported module remained unchanged (Fig. 5 and Fig. 6). During the experiment, 10 vehicles with oversized cargo were transported at night. The experiment was carried out by the GC "MonArch" with the support of the Moscow City Government.
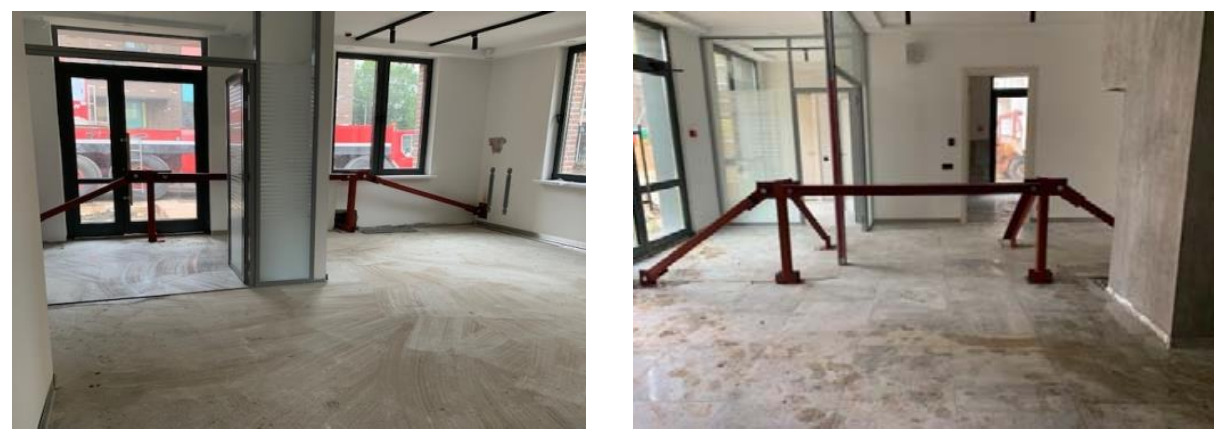

Fig. 5. Installed braces for additional dynamic loads absorption for large modules transportation and installation. 


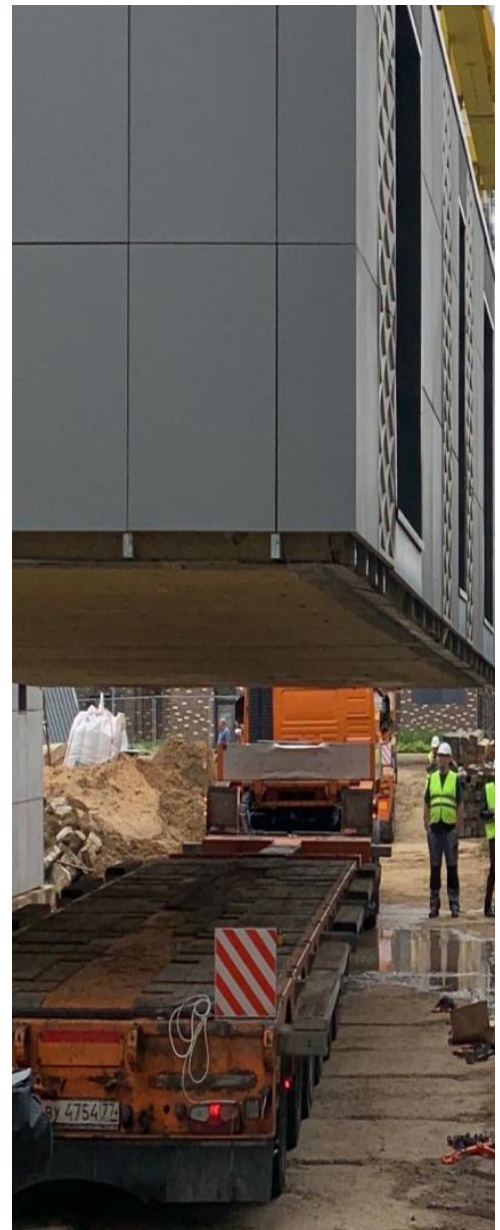

a)

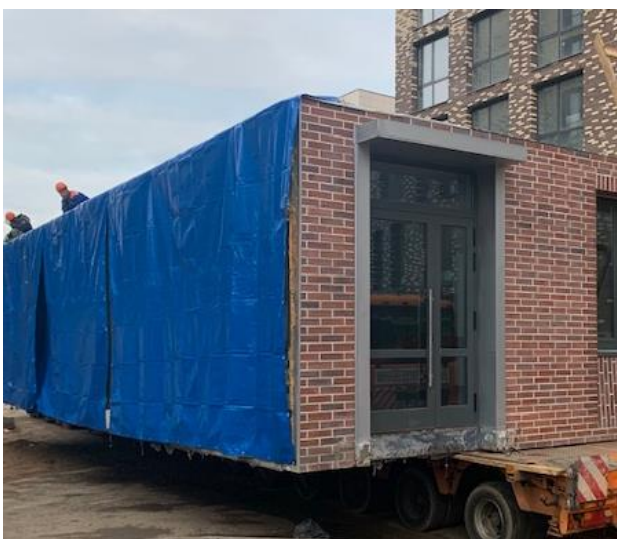

b)

Fig. 6. Test transportation of oversized modules.

a) oversized module installation upon a platform car

b) oversized module transporting on a platform car

3. Considering the issue of mechanization in large-scale housing construction, it is necessary to analyze the experience of using flat structures in panel housing construction $[4,5,10]$. During the construction of large-panel buildings from flat structures, for the first time, the maximum number of storeys (17 floors) was achieved in residential buildings of the P-44 series - a typical series of residential buildings designed in the late 1970s by the Moscow Scientific-Research and Design Institute of Typology and Experimental Design. The buildings of this series were produced by DSK-1 from 1978 to 2016. Buildings of the P-44, P-44T, and P-44K series are a massive series of typical residential buildings built in the city of Moscow and many cities of Russia [6].

After large-panel buildings from flat structures that reached 17 storeys, the buildings with a height of 22 storeys - the KOPE series (mobile space-planning elements) - were designed by the Mosproekt design institute. The construction of panel buildings of the above series was carried out from 1982 to 2015 [2, 3].

It was not possible to achieve a higher height in industrial large-panel buildings of previous generations. Mechanization was also one of the limiting factors. Main equipment tower cranes were designed and mass produced and used, based on the possibility of selecting only certain brands of cranes, such as KB-674 or KB-676. These brands of tower cranes had the required lifting capacity for lifting heavy panels weighing from 6 to 8 tons, 
boom reach of 35 meters. And the lifting height of the crane hook was the most suitable for 22 -storey buildings. The decision to stop at this height was made, and 22-storey buildings were erected.

4. Considering the prospects for the development of large-scale modular housing construction, it is planned to construct buildings with a height of 30 floors.

Analyzing the technical characteristics of cranes for large-scale housing construction, as well as based on modern mechanization, including the availability of modern equipment and cranes of various types, as well as taking into account the variable decisions made in the organizational and technological design, until recently, the maximum assembly of 22 storey buildings was possible. Starting from 2013, Mosproekt OJSC began to increase the number of storeys of the KOPE series from 22 floors to 25 floors. In 2016, the construction of houses from the universal DOMMOS system, which is produced by JSC HC "Main AllRegional Construction Department "Center" with up to 25 storeys, began to appear in large-panel housing construction. The number of storeys was also increased to 25 storeys for single-section residential buildings of the D / DOMKON series and the D-25 N1 series (DOMKON - 1), and 27 storeys for residential buildings of the I 155 MKB series. Residential buildings with a height of 25 floors made of products of JSC "DSK-1" were obtained for the P-44T series. In all the above-described houses, the floor height does not exceed $2.8 \mathrm{~m}$. Residential buildings of large-panel housing construction, despite the efforts of design organizations and builders, could not exceed the maximum number of storeys of 25 - 27 floors in mass industrial housing construction. This stop occurred, among other things, due to the lack of mechanization for the erection of buildings of this type of housing construction.

Thus, having considered the experience in the construction of large-panel buildings from flat structures and considering the prospects for the development of large-scale housing construction, it is assumed that, with the expansion of the technical capabilities of cranes, it is possible to increase the height of buildings in large-scale housing construction, presumably up to 30 floors. Developments in this area are being actively pursued both on the part of design organizations and on the part of making organizational and technological decisions, considering, first of all, the technical capabilities of the cranes and mechanization for the large-scale construction.

5. As a result of solving mechanization issues in large-scale housing construction, the following mechanization options are possible. Regarding the leading machines, it is experimentally shown in the part of the adoption of main design solutions:

- use cranes on a special chassis with a lifting capacity of 500 tons to erect a building with a height of up to 7 floors;

- use caterpillar cranes to erect a building with a height of 7 to 15 floors;

- use a portal system to erect a building with a height of 7 to 30 floors.

\section{Discussion}

As the analysis of the experience of the development of industrial housing construction and the transition to residential buildings of the fifth and sixth generations shows, first, it is necessary to solve the following problems.

The experiment described above showed the need to search for new lightweight building materials, as well as the need for variability in the size of modules for transportation not only in urban conditions, but also in the prospect of construction in mountainous areas.

Also, a methodology for the development of flow diagrams is needed to solve transportation problems with the maximum identification of the conditions necessary for the transportation of oversized modules. 
At the same time, the problem of the possibility of mounting flat structures and large modules at higher elevations requires a solution. However, considering the limitedness of the main characteristics of lifting mechanisms (load capacity, lifting height, lowering depth, reach, etc.), it is necessary to determine the limit of the possibility of installing this type of structure.

In addition, it is necessary to determine the technological equipment for transportation and stiffening the transported modules, as well as to develop sets of removable cargo handling equipment, jacks and other equipment.

It is necessary to formulate requirements for the transformable work technology, including the formation of a construction site. And also, to formulate requirements for the construction of high-quality buildings produced in industrial large-scale housing construction.

\section{Conclusions}

For the implementation of the priority national project "Formation of a comfortable urban environment", first, it is necessary to provide high-quality comfortable housing in a short time. This is due to the above program, which also affects the aspects of new construction in the territories of New Moscow. The promising development of large-scale housing construction is determined by the high rates of construction products manufactured. This makes it possible to quickly develop new construction on the territory of New Moscow.

A significant advantage of large-scale construction lies in the development of new technologies that make it possible to reduce the construction time by 18 times under equal conditions for industrial housing construction in comparison with large-panel housing construction.

The solution of the posed problems related to the transportation of oversized large modules and the determination of the maximum possible height of large-scale buildings will determine the construction methods in the future, set the criteria for technical provisions, and determine the organizational and technological solutions.

We would like to express our gratitude to the organizers of the conference under the guidance of Professor, Doctor of Technical Sciences, Head of the Department of Technology and Organization of Construction Production of NRU MGSU A.A. Lapidus.

We would like to express our gratitude for the opportunity to participate in the experiments and obtain information from the MonArch Group of Companies to the General Director of the MonArch Group of Companies, Professor, Doctor of Technical Sciences, Corresponding Member of the Russian Engineering Academy Ambartsumyan Sergey Aleksandrovich, to the inventor Meshcheryakov Alexander Sergeevich for support in scientific activities.

\section{References}

1. Yu.S. Volkov, Development prospects for prefabricated precast concrete in Russia (VNIINTPI, Moscow, 2000).

2. M.N. Ershov, A.A. Lapidus, V.I. Telichenko, Technological processes in construction Books 1-10 (ASV Publishing House, Moscow, 2016).

3. A.Z. Efimenko, Management, planning and regulation of the production of building products and structures at the enterprises of the building industry (MGSU, Moscow, 2012).

4. A.V. Zakharov, M.P. Leontyeva, Constructive solutions for large panel houses of a new generation Industrial and civil engineering 102016. 
5. N.V. Klyueva, V.I. Kolchunov, A.S. Bukhtiyarova, Resource-energy-saving structural system of residential and public buildings with a given level of structural safety Industrial and civil engineering 2 (2014).

6. S.V. Nikolaev, New generation panel and frame buildings, Housing construction 8 (2013).

7. P.P. Oleynik Organization of work life of builders. Saratov, IPRboks, 2013

8. P.P. Oleynik, B.F. Shirshikov, Complete block method of building objects (IPRboks, Saratov, 2013).

9. L.A. Pakhomova, P.P. Oleynik, Comfortable housing of the new industrial generation Construction production 2 (2020).

10. V.T. Shalenny, O.L. Balakchina, Prefabricated monolithic housing construction (Publishing House "IPR Media", Saratov, 2018). 